Virtual Mentor. July 2003, Volume 5, Number 7.

doi: 10.1001/virtualmentor.2003.5.7.ccas2-0307

Clinical Cases

\title{
Clinician and Researcher
}

\section{The ethical questions surrounding the recruitment of patients for clinical trials become more complicated when the recruiting physicians receive financial benefits for each patient enrolled.}

\author{
Commentary by Timothy F. Murphy, PhD, and Matthew Wynia, MD, MPH
}

Internist Michael Hoover has been in practice in a mid-sized city for 12 years. He is a member of an internal medicine group practice, so he frequently sees patients of his partners when their own physician is unavailable. The group's patients range in age from early 30s to late 80s, the majority are in the 40- to 75-year-old range. Those whom Dr. Hoover sees on a regular basis have hypertension, heart disease, headaches, arthritis, or respiratory and other organ system complaints, often related to aging. Some have cancers; a few have chronic conditions such as diabetes and lupus. Most of the group's patients have some health insurance or Medicare; 8 to 10 percent of care is uncompensated.

Dr. Hoover is prompted to think about the illnesses and demographics of his patients in this way when he receives a letter from a contract research organization that matches pharmaceutical companies that are conducting clinical research to physicians. One of the contract organization's current client companies has an anti-depressant drug in Phase III randomized clinical trials and is looking for physicians who can recruit patients to participate. The company is particularly interested in testing the drug's effectiveness on men. They invite Dr. Hoover to enroll up to 25 participants.

Initially, Dr. Hoover is eager to participate. He has a significant number of male patients who, he thinks, suffer from depression of various kinds - some because they are aging and losing abilities they once had or have chronic illness that brings increasing disability with it. Others because they have lost a wife, or a job, or their rights to see their children. Still others seem depressed regardless of their current life circumstances. Most have been reluctant to try medication or to see counselors of any sort. "If only I could get a good night's sleep," they say, or "had a little more energy," or "had a job," or "could see my kids." They rarely entertain the notion that treating depression might enable them to get more sleep, or a job, or have more energy, because they don't think they're depressed.

Dr. Hoover reckons that, given the good relationship he has with his patients, and by offering them the opportunity to do their part for medical science, he could persuade many of his depressed male patients to participate in the study. As the decision time draws close, however, Dr. Hoover begins to have second thoughts. The pharmaceutical company will pay him \$3,000 for each patient he enrolls in the study. He will follow the participating patients for 2 years. These visits will be free to the participants. Is it taking advantage of his patients' trust that he can probably "persuade" them to participate, he wonders? Does the offer of a free visit every 3 months constitute financial pressure for his jobless patients with depression? Is the $\$ 3,000$ per subject an incentive for him to participate? Will the clinician and researcher roles conflict?

The study is double-blind, so Dr. Hoover will not know which patients are receiving the trial drug and which are not. Dr. Hoover has no financial interest in the company that is conducting the trials, and believes that a good antidepressant with limited side effects would be a therapeutic advantage over what is currently available. If he doesn't participate, will the doctor who the contract organization ends up recruiting handle the patient trust and conflicts of interest issues better than he can? 
Under what conditions, if at all, should Dr. Hoover agree to be a clinician-researcher for the pharmaceutical company testing its anti-depressant drug?

\title{
Commentary 1
}

\author{
by Timothy F. Murphy, PhD
}

Capitation fees are financial incentives that sponsors of clinical trials offer to physicians who help identify and enroll subjects in studies of medical drugs and devices. In the case here, Dr. Hoover might enroll as many as 25 subjects over the course of 2 years. At $\$ 3,000$ per subject, he could take in $\$ 75,000$. The purposes for which this money can be used depend on the rules of his group practice. One use would be to cover the costs of running the study. For example, Dr. Hoover could use the money to hire an assistant to coordinate the study and make sure that appointments are kept and data are sent to the pharmaceutical corporation as appropriate. Some medical practices might allow Dr. Hoover to use any money left over for professional purposes. For example, he could use the money to attend medical conferences and seminars or to buy medical equipment. Depending on the rules of his group practice, he might even be able to use the money as part of his salary or for personal purposes.

Dr. Hoover wonders whether it is ethical to involve his patients in this study or whether he has conflicts of interest, both medical and financial. A conflict of interest involves a situation in which someone has a private or personal interest that could influence the way in which professional decisions are made. In conflicts of interest, people could make decisions that serve their own interests rather than the interests of the people they have an obligation to serve.

The notion of equipoise should be helpful to Dr. Hoover in coming to a decision about whether it is appropriate to enroll his patients in this trial. Equipoise refers to indeterminacy about whether one medical drug or device is better than another. A clinical trial is designed to resolve this uncertainty. Before such studies begin, there should be good reasons for thinking that a new drug should be tested: it has shown strong promise in animals; there are scientific reasons for expecting it to offer superior therapy; or it might be an improvement in that it could be taken only once a day rather than 4 times a day. It is this expectation that the new intervention is superior in some way together with uncertainty about that superiority that justify asking people to enroll in clinical trials. If Dr. Hoover is convinced that there are good reasons to expect this drug to be better in some way than other drugs and that it is unclear whether this new drug is in fact superior, he is justified in asking patients to enroll in the study. In other words, he has no reason to think that he is depriving a patient of a clear benefit by offering that patient the opportunity to take a new-and possibly better-drug.

Enrolling patients will bring money to Dr. Hoover, and he therefore wonders whether capitation fees generate a financial conflict of interest. One danger arising from capitation fees is that Dr. Hoover might be tempted to enroll patients who are not appropriate for this study. The way to control this temptation is to ensure that the study in question has very clearly identified inclusion and exclusion criteria. These criteria spell out the subjects of interest to the research, and when defined in a precise way they can work against dubious enrollment practices. Dr. Hoover should also remember that it is not his decision to enroll patients in the study; that decision belongs to them. To minimize any conflict of interest he should make sure that the patients receive thorough information about the study in a way that lets them decide free from any possible bias from him about the importance of enrolling.

Federal regulations governing clinical research require that researchers disclose certain financial aspects of subjects' involvement: whether they will receive any free care, compensation, or treatment in the case of an emergency. For some people, free medical care-even experimental medical care-can influence decisions about enrolling in clinical trials. To be sure, some people might not get medical care except for their participation in clinical trials. It is not unethical to offer free medical services as part of a clinical trial. If those services cross the line to the point where they have a undue influence in decisions to enter the trials, Dr. Hoover would be right to wonder how free his patients were to make their own decisions about enrolling. Free services should not force people to accept risks they would not otherwise accept.

Federal regulations do not require researchers to disclose capitation fees to subjects, and the vast majority of researchers make no such disclosures. Dr. Hoover is not alone in wondering whether there are ethical concerns here. 
Good practices in study design and informed consent should work to prevent any lapses of judgment on Dr. Hoover's part. However, potential subjects could be in a better position to evaluate for themselves whether the offer of enrollment is disinterested if they knew what benefits the researcher would receive. If Dr. Hoover is worried that capitation fees might influence his judgment in some way, or if Dr. Hoover wanted to avoid even the appearance of a conflict of interest, he could exceed federal requirements and disclose to those patients he considers to be prospective trial participants the terms of his own financial arrangements with the sponsors of the research.

F. Murphy, PhD, is a professor of philosophy in the biomedical sciences at the University of Illinois College of Medicine at Chicago.

\section{Commentary 2}

\section{by Matthew Wynia, MD, MPH}

Doctor Hoover faces a situation that is becoming increasingly common. In the more than 20 years since the Belmont Commission issued its landmark report that laid out ethical considerations for research on humans and resulted in greater government regulation of federally funded research, clinical research has become increasingly commercialized. More clinical research is now performed by private industry than is funded by the government. And more clinical research is moving into individual doctors' offices, away from large academic medical centers. There are many reasons for this, and the trends carry some benefits and some risks.

Clinical trials, wherein real patients affected by an illness agree to try an experimental therapy, provide the clearest and quickest route to demonstrating that a new treatment is safe and effective. Phase III trials, like the one Dr. Hoover is considering, are designed to demonstrate that a new treatment works better than a placebo, or better than standard therapy, and they are required for approval of new drugs by the FDA. Because clinical trials are necessary for regulatory approval, and because the number of potential new treatments under development continues to balloon, demand for clinical trial participants will continue to rise. Clinicians like Dr. Hoover, who does not practice in an academic medical center and has not previously been a clinical researcher, hold the key to enrolling new patients into these trials. Therefore, it is to be expected that future physicians practicing outside of academic medicine will face even more requests to participate, along with their patients, in clinical trials.

In many ways, bringing traditionally "non-academic" clinicians and their patients into the research enterprise represents a potentially healthy democratization of the process. In the past, clinical trials often involved only large academic institutions. But being involved in clinical trials is a useful way for physician participants to keep abreast of new developments. Patients may see the opportunity to enroll in clinical trials as a way to "do their part" for medical science, and they may benefit if the new treatment ends up being better than existing options. Enrolling in clinical trials has been an important avenue to obtain new therapies among patients with HIV infection, for example. For researchers and drug developers, clinical trials that include a broader cross-section of patients may better assess the real-life effectiveness of the treatment under study.

But there are also risks associated with bringing clinicians inexperienced in conducting clinical trials into the clinical trials enterprise. And some of these risks are increased when for-profit corporations are ultimately running the trials.

One risk is that inexperienced clinicians, like their patients, will fall into a "therapeutic misconception" about the trial. That is, they may, perhaps subconsciously, believe that the trial drug being given is already known to be better than existing options. Dr. Hoover might believe this; why else would he believe he could convince his depressed patients to try a new experimental treatment, where he has been unable to convince them to try existing therapies that are already known to be somewhat effective?

As for patients, they are especially likely to mistake an experiment for a therapy when the person asking them to enter the experiment is the same one that usually offers them proven therapies. Patients facing a physician-researcher may not be able to distinguish these different roles. Large academic medical centers are in a better position to address this by having another doctor or nurse who has not been involved in the patient's care help to ensure informed consent when patients are deciding whether to enroll in a trial. But in a small clinic, this may not be an option. Therapeutic 
misconceptions, especially when they are eventually proven wrong, can have serious negative consequences, both on health and on the patient-doctor relationship.

Industry-sponsored trials are prone to additional problems. Bringing a new drug to market is expensive, often costing upwards of \$500 million. It is also time consuming, and many drugs spend years of their limited patent protections awaiting the results of clinical trials before they can finally go on the market. By the time a drug reaches the Phase III clinical trial stage, the company will already have made an extremely large investment, all of which is at risk based on the performance of the drug in the trial. At the same time, good performance in a trial by a new drug to treat a common illness, such as depression, could be worth hundreds of millions or even billions of dollars in profit for the company. Thus, while pharmaceutical companies have clear incentives to produce newer and better treatments, since new and improved products sell, they also have clear incentives to rapidly convince regulators, doctors, and patients that their new and improved drug really is new and improved, perhaps even when it is not.

The pressure to recruit patients quickly and demonstrate good results can lead to inappropriate incentives to recruit trial participants and to designing trials that optimize the chance of a positive results. For instance, a large payment to the physician for recruiting patients may tempt the physician to recruit inappropriate candidates. A rough calculation shows that Dr. Hoover will receive \$3,000 up front for seeing each patient 8 times--a payment of more than \$300 per visit. Presuming that very ill patients will be excluded from the trial, many of these visits should be fairly routine and in some cases the visits might also be billed to, and covered by, insurance. If this is the case, then this payment seems much more than generous--it seems more like a kickback. On the other hand, if Dr. Hoover must establish a new system for following these patients, hire new staff, and so on, then perhaps this level of payment is appropriate. In fact, since this would be his first involvement in a clinical trial, Dr. Hoover probably has little information with which to determine whether the amount is appropriate. He would do well to have his attorney or business manager evaluate the proposed research contract.

Dr. Hoover's inexperience might also lead him to participate in a trial that is methodologically or ethically unsound. Industry-sponsored trials, since they are not federally funded, may not have undergone review by an Institutional Review Board, for example. While we do not know enough about the trial at issue to make a judgment as to its ethical and practical merits, an inexperienced physician might not know what questions to ask. Medical researchers should demand that clinical trials meet ethical standards and that they be designed to provide meaningful new information-not simply to provide information that will allow a new drug to make it to market.

Finally, Dr. Hoover should not be concerned whether another physician might take the contract and be even less prepared to handle these issues. He should be concerned about his own ethical and legal standing, and his relations with his patients. Clinicians outside of academic medical centers can and ought to be involved in clinical trials--but Dr. Hoover should receive training in both the ethics and the practicalities of conducting clinical trials before he signs up to be an investigator.

Matthew Wynia, MD, an internist, is a clinical associate professor of medicine at the University of Chicago and the director of The Institute for Ethics at the American Medical Association.

The people and events in this case are fictional. Resemblance to real events or to names of people, living or dead, is entirely coincidental. The viewpoints expressed on this site are those of the authors and do not necessarily reflect the views and policies of the AMA.

(C) 2003 American Medical Association. All Rights Reserved. 